\title{
Ethnic differences in mortality from sudden infant death syndrome in New Zealand
}

\author{
E A Mitchell, A W Stewart, R Scragg, R P K Ford, B J Taylor, D M O Becroft, J M D Thompson, \\ I B Hassall, D M J Barry, E M Allen, A P Roberts
}

University of Auckland, Auckland, New Zealand E A Mitchell, senior lecturer in paediatrics

A W Stewart, biostatistician $\mathrm{R}$ Scragg, senior lecturer in epidemiology

JM D Thompson,

biostatistician

Christchurch, New

Zealand

R P K Ford, community

paediatrician

University of Otago, Dunedin, New Zealand B J Taylor, senior lecturer in paediatrics

Princess Mary Hospital for Children, Auckland, New Zealand

D M O Becroft, pathologist

Wellington, New Zealand I B Hassall, commissioner for children

A P Roberts, community

paediatrician

\section{Hastings, New Zealand}

D M J Barry, paediatrician

Thames, New Zealand E M Allen, community paediatrician

Correspondence to: Dr E A Mitchell,

Department of Paediatrics, University of Auckland, Private Bag, Auckland 1, New Zealand

BMF 1993;306: 13-6

\section{Abstract}

Objectives-To examine the factors which might explain the higher mortality from sudden infant death syndrome in Maori infants $\mathbf{( 7 \cdot 4 / 1 0 0 0}$ live births in 1986 compared with 3.6 in non-Maori children).

Design-A large nationwide case control study.

Setting-New Zealand. 485 infants who died of sudden infant death syndrome were compared with 1800 control infants. There were 229 Maori and 240 non-Maori cases of sudden infant death syndrome (16 cases unassigned) and 353 Maori and 1410 nonMaori controls (37 unassigned).

Results-Maori infants had 3.81 times the risk ( $95 \%$ confidence interval 3.06 to $4 \cdot 76$ ) of sudden infant death syndrome compared with non-Maori infants. The risk factors for sudden infant death syndrome within groups were remarkably similar. When Maori and non-Maori controls were compared the prevalence of many of the known risk factors was higher in Maori infants. In particular, mothers were socioeconomically disadvantaged, younger, and more likely to smoke and their infants were of lower birth weight and more likely to share a bed with another person. Multivariate analysis controlling for potential confounders found that simply being Maori increased the risk of sudden infant death syndrome by only $1.37(95 \% \mathrm{CI}=0.95$ to 2.01$)$, not statistically significantly different from 1.

Population attributable risk was calculated for prone sleeping position, maternal smoking, not breast feeding, and infants sharing a bed with another person. In total these four risk factors accounted for $89 \%$ of deaths from sudden infant death syndrome in Maori infants and $79 \%$ in nonMaori infants.

Conclusion-The high rate of sudden infant death syndrome among Maori infants is based largely on the high prevalence in the Maori population of the major risk factors. Other risk factors, not related to ethnicity, probably explain remaining differences between Maori and non-Maori children.

\section{Introduction}

Postneonatal mortality in New Zealand is high for a developed country $\left(6 \cdot 2 / 1000\right.$ live births in 1986). ${ }^{1}$ In recent years over $60 \%$ of postneonatal deaths have been due to the sudden infant death syndrome, giving New Zealand probably the highest death rate from sudden infant death syndrome in the developed world (4.0/1000 live births). ${ }^{2}$ Furthermore, within New Zealand the death rate from sudden death infant syndrome differs between ethnic groups, with Maori rates substantially higher than those in non-Maori children (7.4 and 3.6/1000 live births respectively in 1986). ' This ethnic difference has not been explained.
We therefore used data from a large case-control study to look at differences between Maori and non-Maori children and examine factors that might explain the higher mortality from sudden death infant syndrome among Maori children.

\section{Methods}

The New Zealand cot death study has been reported in detail. ${ }^{34}$ It was a large nationwide case-control study that covered $78 \%$ of all live births in New Zealand over three years (1 November 1987 to 31 October 1990). Among the 716 postneonatal deaths there were 485 cases of sudden infant death syndrome in which the diagnosis was agreed by the regional pathologist and the paediatrician. The pathology protocol has been described previously. ${ }^{3}$ Necropsies were carried out in $474(98 \%)$ of the 485 cases attributed to sudden infant death syndrome.

The cases were compared with 1800 control infants, who were randomly selected from all births in the study regions, except home births (less than $1 \%$ ). The following method was used: (a) a date of interview (nominated date) was randomly selected from all 1096 days in the study period, $(b)$ the control was then randomly allocated an age at which to be interviewed, (c) the date of birth was calculated from age and date of interview, (d) an obstetric hospital was randomly chosen in proportion to the number of births in 1986, and $(e)$ random numbers were used to select a particular infant from those born on the date of birth in the nominated obstetric hospital.

Information was collected by examining obstetric records and from interviews with the parents. The questions relating to ethnic group in the interview were: "To which group do you (mother) belong?" and "To which group do you (father) belong?" The choices were that of European, Maori, Pacific Islander, and other (in which case they were asked to specify their race). This information was also obtained from the obstetric records for the mother. There was close agreement between the obstetric records and the interviews. The infant was classified as Maori if either the mother or the father considered themselves to be Maori.

Other variables examined related to the selection process (infant's age, region, and nominated time of day/time of death), sociodemography (occupation, marital status, age mother left school, age of mother), pregnancy (age of mother at first pregnancy, number of previous pregnancies, months pregnant when first attended antenatal clinic, attended antenatal classes), and postnatal factors (infant's sex, birth weight, gestation, admission to special care baby unit, breast feeding only at discharge from obstetric hospital, maternal smoking in last two weeks, season, infant's sleeping position, and infant sharing a bed with 
another person). The definition of these variables has been described. ${ }^{34}$

The $x^{2}$ values are from $2 \times n$ contingency tables comparing the Maori and non-Maori controls. The confidence intervals for the odds ratios were calculated using the method of Cornfield, and the multivariate odds ratio and its confidence interval were obtained from unconditional logistic regression. Population attributable risks, not adjusted for other factors, estimate the proportion of deaths explained by exposure to the risk factor, and the relative attributable risks estimate the percentage of the excess risk in Maori, compared with non-Maori, which could be attributed to a higher exposure to the risk factor in Maori

TABLE I-Number (and percentage) and univariate odds ratios of variables related to sociodemography in non-Maori and Maori children

\begin{tabular}{|c|c|c|c|c|c|c|}
\hline \multirow[b]{2}{*}{ Variable } & \multicolumn{3}{|c|}{ Non-Maori } & \multicolumn{3}{|c|}{ Maori } \\
\hline & Cases & Controls & Odds ratio $(95 \% \mathrm{CI})$ & Cases & Controls & Odds ratio $(95 \% \mathrm{CI})$ \\
\hline \multicolumn{7}{|c|}{ Region } \\
\hline $\begin{array}{l}\text { Auckland } \\
\text { Central North }\end{array}$ & $64(26 \cdot 7)$ & $493(35 \cdot 0)$ & $1 \cdot 00$ & $69(30 \cdot 1)$ & $96(27 \cdot 2)$ & 1.00 \\
\hline $\begin{array}{l}\text { Island } \\
\text { Southern North }\end{array}$ & $54(22 \cdot 5)$ & $335(23 \cdot 8)$ & $1.24(0.83$ to 1.86$)$ & $99(43 \cdot 2)$ & $171(48 \cdot 4)$ & $0.81(0.53$ to 1.22$)$ \\
\hline Island & $31(12 \cdot 9)$ & $228(16 \cdot 2)$ & $1.05(0.65$ to 1.69$)$ & $35(15 \cdot 3)$ & $53(15 \cdot 0)$ & $0.92(0.52$ to 1.61$)$ \\
\hline $\begin{array}{l}\text { Christchurch } \\
\text { Southern South }\end{array}$ & $48(20 \cdot 0)$ & $189(13 \cdot 4)$ & $1.96(1.27$ to 3.01$)$ & $15(6 \cdot 6)$ & $15(4 \cdot 3)$ & $1.39(0.60$ to 3.25$)$ \\
\hline Island & $43(17 \cdot 9)$ & $165(11 \cdot 7)$ & $2 \cdot 01(1 \cdot 28$ to $3 \cdot 14)$ & $11(4 \cdot 8)$ & $18(5 \cdot 1)$ & $0.85(0.35$ to 2.05$)$ \\
\hline $\begin{array}{l}\text { I, II } \\
\text { III, IV } \\
\text { V, VI, others }\end{array}$ & $\begin{array}{r}51(23.9) \\
108(50 \cdot 7) \\
54(25 \cdot 4)\end{array}$ & $\begin{array}{l}505(39 \cdot 1) \\
610(47 \cdot 2) \\
177(13 \cdot 7)\end{array}$ & $\begin{array}{l}\text { Socioeconomic status } \\
1.00 \\
1.75(1.21 \text { to } 2.54) \\
3.02(1.95 \text { to } 4.69)\end{array}$ & $\begin{array}{l}20(11 \cdot 2) \\
67(37 \cdot 6) \\
91(51 \cdot 1)\end{array}$ & $\begin{array}{r}39(13 \cdot 0) \\
143(47 \cdot 8) \\
117(39 \cdot 2)\end{array}$ & $\begin{array}{l}1.00 \\
0.91(0.48 \text { to } 1.76) \\
1.52(0.80 \text { to } 2.90)\end{array}$ \\
\hline \multicolumn{7}{|c|}{ Age mother left school (years) } \\
\hline$<16$ & $67(31 \cdot 3)$ & $236(18 \cdot 3)$ & $2.25(1.55$ to 3.27$)$ & $94(52 \cdot 8)$ & $119(39 \cdot 7)$ & $2.27(1.35$ to 3.82$)$ \\
\hline 16 & $66(30 \cdot 8)$ & $413(32 \cdot 0)$ & $1.27(0.88$ to 1.82$)$ & $53(29 \cdot 8)$ & $92(30 \cdot 7)$ & $1.65(0.94$ to 2.91$)$ \\
\hline$\geqslant 17$ & $81(37 \cdot 9)$ & $643(49 \cdot 8)$ & 1.00 & $31(17 \cdot 4)$ & $89(29 \cdot 7)$ & 1.00 \\
\hline \multicolumn{7}{|c|}{ Married } \\
\hline Yes & $132(61 \cdot 7)$ & $1065(82 \cdot 4)$ & $1 \cdot 00$ & $42(23 \cdot 6)$ & $115(38 \cdot 3)$ & 1.00 \\
\hline No & $82(38 \cdot 3)$ & $227(17 \cdot 6)$ & $2.91(2 \cdot 11$ to 4.02$)$ & $136(76 \cdot 4)$ & $185(61 \cdot 7)$ & $2 \cdot 01(1 \cdot 30$ to $3 \cdot 12)$ \\
\hline \multicolumn{7}{|c|}{ Age of mother at infant birth (years) } \\
\hline$<20$ & $37(15 \cdot 7)$ & $83(5.9)$ & $4.50(2.71$ to 7.47$)$ & $50(21 \cdot 9)$ & $66(18.9)$ & $1.46(0.78$ to 2.74$)$ \\
\hline $20-24$ & $69(29 \cdot 2)$ & $277(19 \cdot 8)$ & $2.51(1.68$ to 3.77$)$ & $88(38.6)$ & $123(35 \cdot 1)$ & $1.38(0.78$ to 2.43$)$ \\
\hline $25-29$ & $77(32 \cdot 6)$ & $507(36 \cdot 2)$ & $1.53(1.04$ to 2.26$)$ & $62(27 \cdot 2)$ & $107(30 \cdot 6)$ & $1.12(0.62$ to 2.02$)$ \\
\hline$\geqslant 30$ & $53(22 \cdot 5)$ & $535(38 \cdot 2)$ & $1 \cdot 00$ & $28(12 \cdot 3)$ & $54(15 \cdot 4)$ & $1 \cdot 00$ \\
\hline
\end{tabular}

TABLE II-Number (and percentage) and univariate odds ratios of variables related to pregnancy in nonMaori and Maori children

\begin{tabular}{|c|c|c|c|c|c|c|}
\hline \multirow[b]{2}{*}{ Variable } & \multicolumn{3}{|c|}{ Non-Maori } & \multicolumn{3}{|c|}{ Maori } \\
\hline & Cases & Controls & Odds ratio $(95 \% \mathrm{CI})$ & Cases & Controls & Odds ratio $(95 \% \mathrm{CI})$ \\
\hline \multicolumn{7}{|c|}{ Age of mother at first pregnancy (years) } \\
\hline$<20$ & $76(32 \cdot 2)$ & $193(13.8)$ & $4 \cdot 60(3 \cdot 12$ to $6 \cdot 78)$ & $116(50 \cdot 9)$ & $151(43 \cdot 1)$ & $1.75(0.97$ to 3.17$)$ \\
\hline $20-24$ & $98(41.5)$ & $485(34 \cdot 6)$ & $2.36(1.66$ to 3.36$)$ & $90(39 \cdot 5)$ & $149(42 \cdot 6)$ & $1.37(0.75$ to 2.52$)$ \\
\hline$\geqslant 25$ & $62(26 \cdot 3)$ & $724(51 \cdot 6)$ & 1.00 & $22(9 \cdot 6)$ & $50(14 \cdot 3)$ & 1.00 \\
\hline \multicolumn{7}{|c|}{ No of previous pregnancies } \\
\hline 0 & $46(19 \cdot 5)$ & $432(30 \cdot 8)$ & 1.00 & $48(21 \cdot 1)$ & $108(30 \cdot 9)$ & 1.00 \\
\hline 1 & $75(31 \cdot 8)$ & $422(30 \cdot 1)$ & $1.67(1.11$ to 2.51$)$ & $49(21 \cdot 5)$ & $81(23 \cdot 1)$ & $1.36(0.81$ to 2.29$)$ \\
\hline 2 & $59(25 \cdot 0)$ & $280(20 \cdot 0)$ & $1.98(1.28$ to 3.06$)$ & $49(21 \cdot 5)$ & $59(16.9)$ & $1.87(1.09$ to 3.21$)$ \\
\hline$\geqslant 3$ & $56(23 \cdot 7)$ & $268(19 \cdot 1)$ & $1.96(1.26$ to 3.05$)$ & $82(35.9)$ & $102(29 \cdot 1)$ & $1.81(1.13$ to 2.90$)$ \\
\hline \multicolumn{7}{|c|}{ Months pregnant when first attended antenatal clinic } \\
\hline $0-3$ & $172(80 \cdot 8)$ & $1112(86 \cdot 3)$ & 1.00 & $96(56 \cdot 1)$ & $206(69 \cdot 6)$ & $1 \cdot 00$ \\
\hline$\geqslant 4$ & $41(19 \cdot 2)$ & $176(13 \cdot 7)$ & $1.51(1.02$ to 2.23$)$ & $75(43.9)$ & $90(30 \cdot 4)$ & $1.79(1.19$ to 2.69$)$ \\
\hline \multicolumn{7}{|c|}{ Attended antenatal classes } \\
\hline Yes & $69(32 \cdot 4)$ & $666(51 \cdot 6)$ & 1.00 & $27(15 \cdot 3)$ & $71(24 \cdot 0)$ & 1.00 \\
\hline No & $144(67 \cdot 6)$ & $625(48 \cdot 4)$ & $2.22(1.62$ to 3.06$)$ & $149(84 \cdot 7)$ & $225(76 \cdot 0)$ & $1.74(1.04$ to 2.93$)$ \\
\hline
\end{tabular}

TABLE III-Number (and percentage) and univariate odds ratios of variables related to infant in non-Maori and Maori children

\begin{tabular}{|c|c|c|c|c|c|c|}
\hline \multirow[b]{2}{*}{ Variable } & \multicolumn{3}{|c|}{ Non-Maori } & \multicolumn{3}{|c|}{ Maori } \\
\hline & Cases & Controls & Odds ratio $(95 \% \mathrm{CI})$ & Cases & Controls & Odds ratio $(95 \% \mathrm{CI})$ \\
\hline \multicolumn{7}{|c|}{ Birth weight (g) } \\
\hline$<2500$ & $40(16.9)$ & $65(4 \cdot 6)$ & $4.91(3.04$ to 7.91$)$ & $42(18.4)$ & $19(5 \cdot 4)$ & $5.89(3.01$ to 11.65$)$ \\
\hline $2500-2999$ & $40(16.9)$ & $183(13 \cdot 1)$ & $1.74(1.13$ to 2.67$)$ & $70(30 \cdot 7)$ & $54(15 \cdot 4)$ & $3.46(2.08$ to 5.75$)$ \\
\hline $3000-3499$ & $70(29 \cdot 7)$ & $468(33.4)$ & $1.19(0.84$ to 1.69$)$ & $65(28 \cdot 5)$ & $141(40 \cdot 3)$ & $1.23(0.78$ to 1.95$)$ \\
\hline$\geqslant 3500$ & $86(36.4)$ & $686(48 \cdot 9)$ & 1.00 & $51(22 \cdot 4)$ & $136(38.9)$ & 1.00 \\
\hline \multicolumn{7}{|c|}{ Gestation (weeks) } \\
\hline $28-33$ & $20(8 \cdot 4)$ & $21(1.5)$ & $6.60(3.36$ to 12.96$)$ & $15(6 \cdot 6)$ & $6(1 \cdot 7)$ & $4.86(1.74$ to 15.54$)$ \\
\hline $34-37$ & $32(13 \cdot 6)$ & $100(7 \cdot 2)$ & $2.22(1.41$ to 3.47$)$ & $46(20 \cdot 4)$ & $20(5 \cdot 8)$ & $4.47(2.48$ to $8 \cdot 12)$ \\
\hline$\geqslant 38$ & $184(78 \cdot 0)$ & $1275(91 \cdot 3)$ & 1.00 & $165(73.0)$ & $321(92 \cdot 5)$ & 1.00 \\
\hline \multicolumn{7}{|c|}{ Infant's sex } \\
\hline Male & $143(60 \cdot 6)$ & $716(51 \cdot 1)$ & $1.47(1.10$ to 1.97$)$ & $140(61 \cdot 4)$ & $172(49 \cdot 1)$ & $1.65(1.16$ to 2.35$)$ \\
\hline Female & $93(39.4)$ & $686(48.9)$ & 1.00 & $88(38.6)$ & $178(50.9)$ & 1.00 \\
\hline
\end{tabular}

children. The methods of calculation for the Cornfield confidence intervals and the population and relative attributable risks are given by Breslow and Day. ${ }^{5}$

\section{Results}

Obstetric records were examined in 465 (96\%) cases and $1762(98 \%)$ controls. Parental interviews were completed in $393(81 \%)$ cases and $1592(88 \%)$ controls.

Infants dying of sudden infant death syndrome included 229 Maoris, 240 non-Maoris, and 16 children who could not be assigned to an ethnic group. There were 353 Maori and 1410 non-Maori controls, with 37 children unassigned. This gave a univariate odds ratio for the risk of sudden infant death syndrome for Maori children of 3.81 ( $95 \%$ confidence interval 3.06 to $4 \cdot 76)$ compared with non-Maori children.

Maori and non-Maori controls were compared in terms of sociodemography, pregnancy, and infant and postnatal factors (tables I-IV). Maori children were significantly more likely to live in the North Island, $\left(\chi^{2}=100, \mathrm{df}=4, \mathrm{p}<0.001\right)$, have lower socioeconomic status $\left(X^{2}=133, \mathrm{df}=2, \mathrm{p}<0.001\right)$, have an unmarried mother $\left(\chi^{2}=247, \mathrm{df}=1, \mathrm{p}<0.001\right)$, have a mother who had left school young $\left(\chi^{2}=78, \mathrm{df}=2, \mathrm{p}<0.001\right)$, and have a mother young at the birth of the infant $\left(\chi^{2}=130\right.$, $\mathrm{df}=3, \mathrm{p}<0.001)($ table I).

Mothers of Maori infants were also significantly younger at their first pregnancy $\left(\chi^{2}=216, d f=2\right.$, $\mathrm{p}<0.001)$, had had more previous pregnancies $\left(\chi^{2}=19\right.$, $\mathrm{df}=3, \mathrm{p}<0.001)$, attended antenatal clinic later $\left(\chi^{2}=48, \mathrm{df}=1, \mathrm{p}<0.001\right)$, and were less likely to have attended antenatal classes $\left(\chi^{2}=74, \mathrm{df}=1, \mathrm{p}<0.001\right)$ (table II).

Maori infants had significantly lower birth weight $\left(\chi^{2}=11 \cdot 4, \mathrm{df}=3, \mathrm{p}<0.010\right)$ (table III). After birth they were more likely to have shared a bed with another person than non-Maori infants $\left(\chi^{2}=42, \mathrm{df}=1\right.$, $p<0.001)$. Maori mothers were significantly more likely to have smoked in the previous two weeks than non-Maori mothers $\left(\chi^{2}=201, \mathrm{df}=3, \mathrm{p}<0.001\right)$ (table IV). There were, however, no differences between the two groups in the sex of infant, gestation, breast feeding, season of nominated date for interview, or sleep position.

Risk factors for sudden infant death syndrome were calculated separately for Maori and non-Maori children. Tables I-IV show the numbers and univariate odds ratios of variables related to the sociodemographic (table I), pregnancy (table II), infant (table III), and postnatal factors (table IV). Risk factors for sudden infant death syndrome were remarkably consistent for both Maori and non-Maori populations within New Zealand.

Multivariate analysis controlling for all the above variables found that being Maori increased the risk of sudden infant death syndrome 1.37 fold $(95 \%$ confidence interval 0.95 to 2.01 ), which was not significantly different from 1 . The presence of a significant interaction $(p=0.007)$ between Maori and non-Maori children was found for bed sharing, indicating that bed sharing was a risk only in the Maori population.

The multivariate analysis included all subjects in the study with full data on all the variables. The Maori children comprised $43 \%$ of those without full data but only $23 \%$ of those with full data. The proportion of cases among those with missing data was disproportionately higher in the Maori group, leading to a greater odds ratio when compared with the non-Maori children (univariate odds ratio of those with full data was $3 \cdot 42$ and for those without full data $4 \cdot 60$ ).

Population attributable risk was calculated for maternal smoking during the past two weeks, not exclusively breast feeding on discharge from the 
TABLE IV-Number (and percentage) and univariate odds ratios of variables related to postnatal factors in non-Maori and Maori children

\begin{tabular}{|c|c|c|c|c|c|c|}
\hline \multirow[b]{2}{*}{ Variable } & \multicolumn{3}{|c|}{ Non-Maori } & \multicolumn{3}{|c|}{ Maori } \\
\hline & Cases & Controls & Odds ratio $(95 \% \mathrm{CI})$ & Cases & Controls & Odds ratio $(95 \% \mathrm{CI})$ \\
\hline \multicolumn{7}{|c|}{ Infant admitted to special care baby unit } \\
\hline Yes & $52(22 \cdot 0)$ & $175(12 \cdot 5)$ & $1.98(1.38$ to 2.83$)$ & $64(28 \cdot 1)$ & $39(11 \cdot 1)$ & $3.11(1.96$ to 4.95$)$ \\
\hline No & $184(78 \cdot 0)$ & $1223(87.5)$ & 1.00 & $164(71.9)$ & $311(88.9)$ & $1 \cdot 00$ \\
\hline \multicolumn{7}{|c|}{ Breast feeding only at discharge from obstetric hospital } \\
\hline Yes & $169(72 \cdot 2)$ & $1177(84 \cdot 1)$ & 1.00 & $146(64 \cdot 9)$ & $288(82 \cdot 8)$ & 1.00 \\
\hline No & $65(27 \cdot 8)$ & $222(15 \cdot 9)$ & $2.04(1.46$ to 2.84$)$ & $79(35 \cdot 1)$ & $60(17 \cdot 2)$ & $2.60(1.73$ to 3.91$)$ \\
\hline \multicolumn{7}{|c|}{ Maternal smoking in last two weeks (cigarettes/day) } \\
\hline Nil & $100(46 \cdot 7)$ & $977(75 \cdot 7)$ & 1.00 & $31(17 \cdot 4)$ & $104(34 \cdot 7)$ & 1.00 \\
\hline $1-9$ & $43(20 \cdot 1)$ & $127(9 \cdot 8)$ & $3.31(2.17$ to 5.04$)$ & $36(20 \cdot 2)$ & $63(21 \cdot 0)$ & $1.92(1.04$ to 3.54$)$ \\
\hline $10-19$ & $35(16.4)$ & $106(8 \cdot 2)$ & $3.23(2.04$ to 5.08$)$ & $59(33 \cdot 2)$ & $91(30 \cdot 3)$ & $2.18(1.26$ to 3.78$)$ \\
\hline$\geqslant 20$ & $36(16 \cdot 8)$ & $81(6 \cdot 3)$ & $4.34(2.72$ to 6.92$)$ & $52(29 \cdot 2)$ & $42(14 \cdot 0)$ & $4 \cdot 15(2 \cdot 26$ to $7 \cdot 67)$ \\
\hline \multicolumn{7}{|c|}{ Season of death/nominated date } \\
\hline $\mathrm{Jan} /$ February & $20(9 \cdot 3)$ & $205(15.9)$ & 1.00 & $20(11 \cdot 2)$ & $47(15 \cdot 7)$ & 1.00 \\
\hline Dec/March & $32(14.9)$ & $217(16 \cdot 8)$ & $1.51(0.81$ to 2.84$)$ & $17(9 \cdot 6)$ & $69(23.0)$ & $0.58(0.26$ to 1.30$)$ \\
\hline Nov/April & $25(11 \cdot 7)$ & $201(15 \cdot 6)$ & $1.27(0.66$ to 2.48$)$ & $25(14 \cdot 0)$ & $47(15 \cdot 7)$ & $1.25(0.58$ to 2.71$)$ \\
\hline October/May & $51(23 \cdot 7)$ & $238(18 \cdot 4)$ & $2.20(1.23$ to 3.95 & $29(16 \cdot 3)$ & $51(17 \cdot 0)$ & $1.34(0.63$ to 2.84$)$ \\
\hline September/June & $37(17 \cdot 3)$ & $211(16 \cdot 3)$ & $1.80(0.97$ to 3.33$)$ & $34(19 \cdot 1)$ & $37(12 \cdot 3)$ & $2 \cdot 16(1.01$ to 4.63$)$ \\
\hline August/July & $49(22 \cdot 9)$ & $220(17 \cdot 0)$ & $2 \cdot 28(1 \cdot 27$ to $4 \cdot 13)$ & $53(29 \cdot 8)$ & $49(16 \cdot 3)$ & $2 \cdot 54(1.26$ to $5 \cdot 15)$ \\
\hline \multicolumn{7}{|c|}{ Position infant placed to sleep at death/nominated time } \\
\hline Prone & $148(69 \cdot 2)$ & $421(32 \cdot 8)$ & $10 \cdot 14(4 \cdot 67$ to $26 \cdot 10)$ & $102(59 \cdot 0)$ & $100(33 \cdot 4)$ & $4.27(2.00$ to 9.30$)$ \\
\hline Side & $59(27 \cdot 6)$ & $662(51 \cdot 5)$ & $2.57(1.15$ to 6.78$)$ & $60(34 \cdot 7)$ & $153(51 \cdot 2)$ & $1.64(0.76$ to 3.61$)$ \\
\hline Back & $7(3 \cdot 3)$ & $202(15 \cdot 7)$ & 1.00 & $11(6 \cdot 4)$ & $46(15 \cdot 4)$ & 1.00 \\
\hline \multicolumn{7}{|c|}{ Sharing bed with another person } \\
\hline Yes & $17(7 \cdot 9)$ & $104(8 \cdot 1)$ & $0.98(0.55$ to 1.72$)$ & $77(43 \cdot 8)$ & $62(20 \cdot 8)$ & $2.96(1.93$ to 4.55$)$ \\
\hline No & $197(92 \cdot 1)$ & $1182(91 \cdot 9)$ & 1.00 & $99(56 \cdot 2)$ & $236(79 \cdot 2)$ & 1.00 \\
\hline
\end{tabular}

TABLE V-Population attributable risk by ethnic group for each of four factors amenable to change

\begin{tabular}{lcc}
\hline & $\begin{array}{c}\% \\
\text { Non-Maori }\end{array}$ & $\begin{array}{c}\% \\
\text { Maori }\end{array}$ \\
\hline Maternal smoking during past 2 weeks & 38 & 50 \\
Not exclusive breast feeding on discharge & 14 & 22 \\
Prone sleep position & 54 & 38 \\
Infant sharing bed with other person & 0 & 29 \\
\hline
\end{tabular}

obstetric hospital, sleeping prone, and the infant sharing a bed with another person (table $\mathrm{V}$ ). In total these four risk factors accounted for $89 \%$ of Maori and $79 \%$ of non-Maori sudden infant deaths. The relative attributable risks for Maori children compared with non-Maori children were $57 \%$ for the higher rate of maternal smoking and $22 \%$ for the higher rate of bed sharing. This was not calculated for sleep position and breast feeding because of the similar exposure distribution of these two variables among Maori children and their controls (table IV).

\section{Discussion}

Mortality from sudden infant death syndrome varies between countries. ${ }^{16-13}$ Although infant care practices, such as infants' sleeping position, vary between countries, comparisons are difficult as socioeconomic, cultural, and environmental factors and temperature also vary greatly. Comparisons between ethnic groups in the same country are, however, more meaningful as broad environmental factors are eliminated.

Ethnic differences in mortality from sudden infant death syndrome have been reported from several countries..$^{8-13}$ In the United States high mortality from sudden infant death syndrome among black infants has been attributed only in part to lower birth weight and socioeconomic disadvantage. ${ }^{8}$ In Birmingham, England, Asian infants had a lower mortality from sudden infant death syndrome than white children, even after crowding, birth weight, maternal age, social class, and infant sex were controlled for. ${ }^{11}$ In New Zealand mortality from sudden infant death syndrome has been known to be higher in Maori children for some time, but the reason has been unclear. ${ }^{1-4}{ }^{12}$ Although this study relates to ethnic differences in New Zealand, the findings may apply in other countries where there are ethnic differences in mortality rates from sudden infant death syndrome.
We calculated the risk factors for sudden infant death syndrome separately for Maori and non-Maori children, and the striking feature was the similarity of the risk factors, with the exception of infants sharing the bed with another person. The failure to identify bed sharing as a risk factor in non-Maori children was probably due to the very small proportion of infants in this group who both shared a bed and were exposed to maternal smoking. Further analyses suggest that exposure to both factors is required for bed sharing to be associated with a raised risk of sudden infant death syndrome (unpublished results).

Despite the similarity of risk factors, the prevalence of many of these risk factors was higher in Maori children than in non-Maori children. Logistic regression analysis showed that ethnic group was not a significant risk factor for sudden infant death syndrome when region, socioeconomic status, the age the mother left school, the age of the mother at the birth of the infant, the age of the mother at first pregnancy, the number of previous pregnancies, antenatal clinic attendance, antenatal class attendance, infant sex, birth weight, gestation, admission to neonatal unit, breast feeding, season, the age of the infant, maternal smoking, sleep position, and sharing a bed with another person were controlled for.

The addition of subjects with missing data could, however, have changed the picture and made ethnicity a significant variable. If being Maori were a significant variable this might arise because of an inherent effect of being Maori or because there are other confounding variables that have not been considered that could explain the difference between Maori and non-Maori children.

Our calculations of relative attributable risk suggest that increased smoking by Maori mothers explained about half $(57 \%)$ of the excess risk of sudden infant death syndrome among Maori children. The same calculation for sharing a bed $(22 \%)$ should be viewed with caution since the ethnically specific relative risks associated with this factor do not appear to be homogeneous.

Population attributable risk provides an indication of the impact that controlling a causal factor might have on the incidence of sudden infant death syndrome. The national cot death prevention programme is attempting to reduce the prevalence of four modifiable risk factors-namely, maternal smoking, lack of breast feeding, prone sleep position, and infant sharing a bed with another person. ${ }^{15}$ In total these four risk factors may account for $89 \%$ of deaths from sudden infant death syndrome in Maori infants and $79 \%$ in nonMaori infants. This, of course, assumes that these variables are causally related to sudden infant death syndrome and are independent. If these four risk factors were eliminated then mortality from sudden infant death syndrome could be reduced to $0 \cdot 8 / 1000$ for both Maori and non-Maori infants.

We conclude that the high rate of sudden infant death syndrome among Maori infants has much of its foundation in the high prevalence in the Maori population of the major risk factors, and other risk factors, not related to ethnicity, probably explain remaining differences between Maori and non-Maori children.

This study was funded by the Health Research Council of New Zealand (HRCNZ) and the Hawkes Bay Medical Research Foundation. Mrs C Everard coordinated the study. Mrs Everard, Mr Thompson, and Mr Stewart were funded by HRCNZ.

1 National Health Statistics Centre. Fetal and infant deaths 1986. Wellington: National Health Statistics Centre, 1988.

2 Mitchell EA, Scragg R, Stewart AW, Becroft DMO, Hassall IB, Ford RPK, et al. Cot death: the New Zealand Study. Contemporary Health Issues et al. Cot death:

3 Mitchell EA, Scragg R, Stewart AW, Becroft DMO, Taylor BJ, Ford RPK, 
et al. Results from the first year of the New Zealand cot death study. NZ Med f 1991;104:71-6.

4 Mitchell EA, Taylor BJ, Ford RPK, Stewart AW, Becroft DMO, Thompson JMD, et al. Four modifiable and other major risk factors for cot death: the New Zealand Study. I Paediatr Child Health 1992;28(suppl 1):S3-8.

5 Breslow NE, Day NE. Statistical methods in cancer research. Vol 1. The analysi of case-control studies. Lyon: IARC, 1980:74-8, 133-4 (IARC Scientific Publication No 32)

6 Lee NNY, Chan YF, Davies DP, Lau E, Yip DCP. Sudden infant death syndrome in Hong Kong: confirmation of low incidence. BMF 1989;298 721

7 Beal SM. Sudden infant death syndrome: epidemiological comparisons between South Australia and communities with a different incidence. Aust Paediatr f 1986;22(suppl):13-6.

8 Black L, David RJ, Brouilette RT, Hunt CE. Effects of birth weight and ethnicity on incidence of sudden infant death syndrome. 7 Pediat 1986;108:209-14
9 Kraus JF, Greenland S, Bulterys M. Risk factors for sudden infant death syndrome in the US collaborative perinatal project. Int $f$ Epidemiol 1989;18: $113-20$.

10 Balarajan R, Raleigh VS, Botting B. Sudden infant death syndrome and post neonatal mortality in immigrants in England and Wales. BMF 1989;298: 716-20

11 Kyle D, Sunderland R, Stonehouse M, Cummins C, Ross O. Ethnic differences in incidence of sudden infant death syndrome in Birmingham. Arch Dis Child 1990;65:830-

12 Borman B, Fraser J, de Boer G. A national study of sudden infant death syndrome in New Zealand. NZ Med f 1988;101:413-5.

13 Tangermann R, McCarthy B, Schmidt E, Limbacher M. Zur hohen Nachsterblichkeit der Suglinge in NRW. Monatsschr-Kinderheilkd 1987; 135:679-85.

(Accepted 14 October 1992)

\title{
Sudden infant death syndrome: links with infant care practices
}

\author{
M Gantley, D P Davies, A Murcott
}

\begin{abstract}
Objectives-To investigate infant care practices in a small ethnic minority population within Britain that might suggest possible factors contributing to the low incidence of the sudden infant death syndrome in Asian populations.
\end{abstract}

Design-Ethnographic interviewing, a qualitative comparative method drawn from social anthropology.

Setting-Central Cardiff.

Subjects-Non-random sample of 60 mothers of Bangladeshi or Welsh ethnic origin and working or middle class occupational status, who had infants under one year old. None of the families interviewed had experienced a sudden infant death.

Results-Broad cultural contrasts emerged as a series of themes from the interview data: living patterns, family networks, sleeping patterns, and concepts of time and dependence.

Conclusion-Bangladeshi infants were cared for in a consistently rich sensory environment; Welsh infants, in contrast, were more likely to experience alternating periods of high and low sensory input. Long periods of lone quiet sleep may be one factor that contributes to a higher rate of sudden deaths in white than in Asian infants.

\section{Introduction}

Sudden infant death syndrome-the sudden, unexpected, and unexplained death of an apparently healthy baby-remains the single most important cause of death in the United Kingdom of children aged between 1 and 12 months.' Research on its aetiology has focused, at one end of the spectrum, on causal mechanisms-for example, inherited metabolic diseases ${ }^{2}$-and, at the other end, on infant care practices that may be potentially protective or harmful, such as sleeping position. ${ }^{3}$

There is now increasing evidence of both national and regional variation in incidence. The syndrome is, for example, very rare in Hong Kong. ${ }^{45}$ Within Great Britain, data from the Office of Population Censuses and Surveys for the years 1982-5 (classified by mother's country of birth) indicate significantly lower rates among babies of mothers born in Africa or Asia (India, Pakistan, or Bangladesh) than in those of mothers born in the United Kingdom or the Republic of Ireland. ${ }^{6}$ In Birmingham, for 1981-3, with ethnicity classified by mother's own report, incidence of deaths from the syndrome was found to be lowest among Asian babies and highest among Afro-Caribbeans, with white infants falling in between. ${ }^{7}$ In east London between 1987 and 1990 the largest ethnic minority population, Bangla- deshis, had rates approximately half those of the white majority (L Hilder, unpublished data). Among Asian populations in the United States (Asian in this case referring to Chinese, Japanese, Vietnamese, or Philippino, defined by mother's own report), the incidence of the sudden infant death syndrome increased with period of residence. ${ }^{8}$

British research also provides information on neonatal deaths for Asian and white infants. OPCS data show higher neonatal deaths among Bangladeshi babies in 1981-3, but comparable rates in 1984-8. In Birmingham the rate of sudden infant deaths was low in Asian infants but there were high rates of congenital malformations resulting in perinatal mortality. In east London neonatal mortality among white and Asian groups was broadly similar. This evidence is not sufficient to suggest that low rates of sudden deaths in Bangladeshi infants are achieved at the expense of high neonatal mortality. It does reinforce the need for detailed local statistics, with ethnicity recorded by personal report rather than by country of birth

The relatively low incidence of the sudden infant death syndrome among Bangladeshi babies in Britain represents something of a paradox, since many of these babies grow up in conditions that would predict a relatively higher incidence of the syndrome. ${ }^{9} 10$ These include poorer socioeconomic conditions, apparently crowded housing, and young mothers often with many children. This paradox has prompted research on the potential contribution of varying infant care practices to the prevention of deaths from this syndrome. Rather than retrospective studies of infants who have died or epidemiological analyses of the sudden infant death syndrome in specific population groups, our research offers a complementary perspective. Recognising that the apparently low incidence of the sudden infant death syndrome was difficult to explain wholly in terms of currently recognised risk factors, we sought to identify other differences in infant care practices that may contribute to the lower incidence of such deaths in Bangladeshi babies. For this reason we did not work with families who had lost an infant: instead we investigated the ordinary patterns of beliefs about infants and their care in two different populations, mothers of Welsh and Bangladeshi infants in Cardiff.

THEORETICAL BACKGROUND: AN ANTHROPOLOGICAL PERSPECTIVE

In 1991 the Lancet carried a series of articles on medical anthropology arguing that "medical anthropology has now emerged as a potential focus for those interested in explaining disease in terms of the patient's cultural context." This paper is part of the emergent contribution of medical anthropology, and presents an
School of Hygiene and

Tropical Medicine, Keppe

BMF 1993;306:16-20 